\title{
Gender Difference in Albuminuria and Ischemic Heart Disease in Type 2 Diabetes
}

\author{
Manouchehr Nakhjavani, MD; Afsaneh Morteza, MD, MPH; Yaser Jenab, MD; Azam Ghaneei, MD; \\ Alireza Esteghamati, MD; Maryam Karimi, BS; and Alireza Farokhian, MD
}

Objective: The value of urinary albumin excretion in the prediction of myocardial ischemia in men and women with type 2 diabetes is not well understood. We questioned whether gender influences the albuminuria-ischemic heart disease relationship in patients with type 2 diabetes.

Methods: We designed a matched case-control study of 926 patients with albuminuria (cases) and 926 age and body mass index matched patients without albuminuria (controls). Ischemic heart disease was defined as the presence of (I) history of angina pectoris or angina equivalent symptoms and critical care unit admission, (2) myocardial infarction and/or electrocardiographic evidence of Q-wave myocardial infarction, (3) coronary revascularization and/or stenting, (4) positive myocardial singlephoton emission computed tomography scan, (5) ischemic ST-segment or T-wave changes, and (6) positive stress testing.

Results: Patients with albuminuria had a lower glomerular filtration rate and a longer diabetes duration than patients without albuminuria. In the group of cases, there were a greater number of men with ischemic heart disease (I20 of $370 ; 32.4 \%$ ) compared to women (97 of 559 ; 17.4\%) $(P<0.00 \mathrm{I})$. The odds ratio of having ischemic heart disease according to the presence or absence of albuminuria was I.25 [95\% Cl: I.0I-I.56] $(P<0.05)$ in all studied populations, 0.79 [95\% Cl: $0.5 \mathrm{I}-\mathrm{I} .2 \mathrm{I}]$ $(P=0.14)$ in women, and 2.84 [95\% Cl: 1.68-4.79] $(P<0.00 \mathrm{I})$ in men. We showed that diabetes duration, high-density lipoprotein, low-density lipoprotein, and hemoglobin $A_{I c}$ influence albuminuria in women, while diabetes duration, fasting blood sugar, and diastolic blood pressure influence albuminuria in men.

Conclusions: Men with albuminuria are at increased risk of ischemic heart disease compared to women. This may be related to the role of high-density lipoprotein on the albuminuria-gender relationship.

Keywords: Albuminuria; Gender differences; Ischemic heart disease

\begin{abstract}
A an index of endothelial cell dysfunction ${ }^{1}$ Abnormally elevated rates of albumin excretion reflect endothelial dysfunction or other vascular damage that is more severe in type 2 diabetes. ${ }^{1,2}$ Albuminuria in hypertensive patients is associated with altered lysosomal activity and transforming growth factor beta 1 (TGF- $\beta 1$ ) expression. ${ }^{3}$ Studies have substantially shown an increased risk of renal damage in the presence of cardiovascular risk factors in normal subjects as well as those with type 2 diabetes. ${ }^{4,5}$ Ischemic heart disease

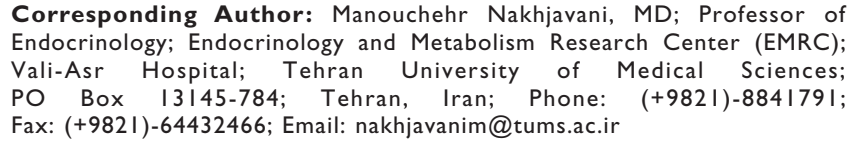
Endocrinology; Endocrinology and Metabolism Research Center (EMRC); Vali-Asr Hospital; Tehran University of Medical Sciences; PO Box 13145-784; Tehran, Iran; Phone: (+982I)-884I79I; Fax: (+982I)-64432466; Email: nakhjavanim@tums.ac.ir

is the major cause of morbidity and mortality in patients with type 2 diabetes, especially in those with elevated levels of urinary albumin excretion. ${ }^{6,7}$ It is known that there are gender differences in the progression of micro-albuminuria and cardiovascular mortality in patients with type 2 diabetes. ${ }^{8-12}$

In patients with type 1 diabetes, male gender, independent of age, is a significant predictor of albuminuria progression, metabolic control, duration of diabetes, and baseline albumin excretion rate. ${ }^{13-15}$ There are limited studies with conflicting

Received: May 10, 2011

Ist Revision: August 12, 2011

2nd Revision: September 8, 201।

Accepted: September 21, 20II

doi: $10.3121 / \mathrm{cmr} .20 \mid 1.1021$ 
Table 1. Demographic and anthropometric parameters, cardiovascular risk factors, and diabetic complications in the study groups.

\begin{tabular}{|c|c|c|c|}
\hline & $\begin{array}{l}\text { With albuminuria } \\
\qquad(n=926)\end{array}$ & $\begin{array}{l}\text { Without albuminuria } \\
\qquad(\mathrm{n}=926)\end{array}$ & $P$ value \\
\hline Age (years) & $59.64 \pm 2.80$ & $56.27 \pm 0.549$ & NS \\
\hline Diabetes duration (years) & $10.03 \pm 0.42$ & $7.94 \pm 0.43$ & $<0.05$ \\
\hline Systolic blood pressure (mmHg) & $124.31 \pm 2.84$ & $123.78 \pm 1.10$ & NS \\
\hline FBS (mg/dL) & $192.90 \pm 11.85$ & $172.95 \pm 3.66$ & NS \\
\hline $\mathrm{HbA}_{1 \mathrm{c}}(\%)$ & $8.68 \pm 0.326$ & $8.33 \pm 0.10$ & NS \\
\hline Creatinine (mg/dL) & $1.19 \pm 0.043$ & $1.00 \pm 0.026$ & $<0.05$ \\
\hline Cholesterol (mg/dL) & $178.03 \pm 7.48$ & $184.64 \pm 2.92$ & NS \\
\hline LDL-C (mg/dL) & $99.38 \pm 4.75$ & $103.82 \pm 2.70$ & NS \\
\hline
\end{tabular}

BMI, body mass index; FBS, fasting blood sugar; $\mathrm{HbA}_{1 \mathrm{C}}$, hemoglobin $\mathrm{A}_{1 \mathrm{C}}$; HDL-C, high density lipoprotein-cholesterol; LDL-C, low density lipoprotein-cholesterol; GFR, glomerular filtration rate; NS, non-significant

Groups are matched for age and BMI.

Quantitative variables are expressed as mean \pm standard error of mean.

reports in type 2 diabetes. ${ }^{10-12}$ The diversity of results in the different reports may be due to the confounding effect of gender on cardiovascular risk factors such as dyslipidemia and albuminuria. ${ }^{16,17}$ In this study we aimed to examine the value of albuminuria in the prediction of ischemic heart disease in men and women with type 2 diabetes.

\section{Methods}

The study was designed in a cross-sectional, matched casecontrol fashion to examine the importance of albuminuria in the prediction of ischemic heart disease. From the records of diabetic patients admitted to Vali Asr hospital during the period from January 2008 to December 2010, information was obtained on all patients with and without albuminuia. For each case, one control matched by age and body mass index (BMI) was randomly selected. Using this database, information from 926 cases defined as patients with albuminuria and 926 age and BMI-matched controls was obtained. Normo-, microand macro-albuminuria were defined as urinary albumin excretion rate $<30 \mathrm{mg} / 24 \mathrm{~h}$, between $30-300 \mathrm{mg} / 24 \mathrm{~h}$, and $>300 \mathrm{mg} / 24 \mathrm{~h}$, respectively. Albuminuria was defined as the presence of micro-/macro-albuminuria. Patients were instructed in the collection of timed 24-hour urine for the measurement of urinary albumin excretion and were instructed to return on the morning after the end of the urine collection. Ischemic heart disease was defined as (1) history of angina pectoris or angina equivalent symptoms and critical care unit admission, (2) myocardial infarction and/or electrocardiographic evidence of Q-wave myocardial infarction, (3) coronary revascularization and/or stenting, (4) positive myocardial single-photon emission computed tomography scan, (5) ischemic ST-segment or T-wave changes, and (6) positive stress testing.
Diabetes was diagnosed according to the criteria of the American Diabetes Association. ${ }^{18}$ Exclusion criteria were type 1 diabetes, acute or chronic renal failure, glomerulonephritis, congestive heart failure, acute infections, pregnancy, diabetic ketoacidosis, non-ketotic hyperosmolar diabetes, thyroid disorders, complete left bundle branch block, and hospital admission during the previous three months. None of the studied women were on hormone replacement therapy. The glomerular filtration rate (GFR) was calculated using the Cockcroft-Gault formula. ${ }^{19}$

Demographic and anthropometric data including age, sex, duration of diabetes, height, waist circumference, weight in light clothing, and blood pressure in sitting position were recorded. Blood pressure was measured twice after 5 minutes and then averaged. The BMI $\left(\mathrm{kg} / \mathrm{m}^{2}\right)$ was calculated according to the Quetelet formula. ${ }^{20}$ All participants gave written informed consent before participation. This research was carried out according to the principles of the declaration of Helsinki, and the local ethics review committee of Tehran University of Medical Science approved the study protocol.

Blood samples were collected after approximately 12 hours of fasting. Serum creatinine, fasting blood sugar (FBS), total cholesterol, triglyceride (TG), high-density lipoprotein cholesterol (HDL), low-density lipoprotein cholesterol (LDL), and hemoglobin $\mathrm{A}_{1 \mathrm{c}}\left(\mathrm{HbA}_{1 \mathrm{c}}\right)$ were measured. Glucose measurements (intra-assay coefficient of variation [CV] $2.1 \%$, inter-assay $\mathrm{CV} 2.6 \%$ ) were carried out using the glucose oxidase method. Creatinine was measured using calibrated Jaffe method (Parsazmoon, Karaj, Iran). Cholesterol, HDL, LDL, and TG were determined using direct enzymatic methods (Parsazmun, Karaj, Iran). $\mathrm{HbA}_{1 \mathrm{c}}$ was estimated by 
Table 2. Association of ischemic heart disease with presence or absence of albuminuria.

\begin{tabular}{|c|c|c|c|c|c|c|c|}
\hline & & \multicolumn{6}{|c|}{ Albuminuria } \\
\hline & & \multicolumn{2}{|c|}{ Women $(n=1056)$} & \multicolumn{2}{|c|}{ Men $(n=796)$} & \multicolumn{2}{|c|}{ Total $(n=1852)$} \\
\hline & & Neg & Pos & Neg & Pos & Neg & Pos \\
\hline \multirow{2}{*}{$\begin{array}{l}\text { Myocardial } \\
\text { Ischemia }\end{array}$} & Neg & 398 & 462 & 342 & 247 & 740 & 709 \\
\hline & Pos & 99 & 97 & 87 & 120 & 186 & 217 \\
\hline
\end{tabular}

Neg, negative; Pos, positive

high-pressure liquid chromatography (HPLC) method. Serum creatinine was measured using direct colorimetric method.

\section{Statistical Analysis}

The statistical package SPSS 16 for windows (Chicago, Illinois, USA) was used for the primary analysis of the cases and controls. Standard statistical methods were used for the analysis of matched case-control studies using STATA/SE for windows (Texas, USA). The data were individually matched. All 926 cases and controls were eligible for the analysis. Quantitative variables are presented as mean \pm standard error of mean. Qualitative variables are presented as number and percent. Independent sample $t$ test (for quantitative variables) and Chi square test (for qualitative variables) were employed to compare cases and controls. To provide a measure of association of albuminuria and the presence of ischemic heart disease, conditional logistic regression was employed. Conditional logistic regression was also used for modeling the variables influencing the albuminuria-gender relationship. A forward stepwise procedure was employed, using $\mathrm{HbA}_{1 \mathrm{c}}$, HDL, LDL, TG, cholesterol, FBS, diabetes duration, and systolic and diastolic blood pressure. Variables with $P<0.2$ in the primary analysis were included in the model until a final best model was achieved. The studied variables, except FBS and diabetes duration, were categorized and included in the model. The cut points for the categorization of the variables were: HDL, $40 \mathrm{mg} / \mathrm{dL}$; LDL, $100 \mathrm{mg} / \mathrm{dL} ; \mathrm{HbA}_{1 \mathrm{c}}, 7 \%$; TG, $150 \mathrm{mg} / \mathrm{dL}$; cholesterol, $150 \mathrm{mg} / \mathrm{dL}$; systolic blood pressure, $130 \mathrm{mmHg}$; and diastolic blood pressure, $80 \mathrm{mmHg}$.

\section{Results}

Demographic, biochemical, and clinical characteristics of participants are illustrated in table 1 . The frequency of insulin therapy was $20 \%$ (185 of 926) in patients with albuminuria and 23\% (213 of 926) in patients without albuminuria. Fortysix percent (852 of 1852) of the patients were on statin therapy, and 52\% (963 of 1852) were on antihypertensive treatment. Approximately $30 \%$ (556 of 1852) of all patients were on insulin therapy.

Patients with albuminuria had a lower glomerular filtration rate (GFR) and longer diabetes duration than patients without albuminuria (table 1). To study the distribution of risk factors between men and women, the studied population was stratified according to gender. In patients with albuminuria, women had a lower GFR compared to men $(45.9 \pm 2.1$ vs. $57.4 \pm 2.1)$ $(P<0.001)$. In patients without albuminuria, women had a lower GFR $(61.3 \pm 1.5$ vs. $66.2 \pm 1.4)(P<0.05)$ and higher cholesterol levels $(192.04 \pm 3.50$ vs. $173.13 \pm 4.92)(P<0.001)$ than men with albuminuria. In the group of patients with albuminuria, there were a greater number of men with ischemic heart disease (120 of $370 ; 32.4 \%)$ compared to women $(97$ of $559 ; 17.4 \%)(P<0.001)$. The odds ratio of having ischemic heart disease according to the presence or absence of albuminuria was 1.25 [95\% CI: 1.01-1.56] $(P<0.05)$ in all studied populations, 0.79 [95\% CI: 0.51-1.21] $(P=0.14)$ in women, and 2.84 [95\% CI: 1.68-4.79] $(P<0.001)$ in men. Table 2 presents the number of patients with ischemic heart disease according to the presence or absence of

Table 3. Conditional logistic regression was employed to study variables influencing albuminuria in patients with type 2 diabetes stratified according to gender.*

\begin{tabular}{clll}
\hline & & Odds ratio $(95 \%$ Cl) & P value \\
\hline \multirow{3}{*}{ Men } & Diabetes duration (years) & $1.007(0.99-1.010)$ & 0.109 \\
& FBS $(\mathrm{mg} / \mathrm{dL})$ & $1.106(1.001-1.203)$ & 0.022 \\
& Diastolic blood pressure $(>80 \mathrm{mmHg})$ & $1.544(0.894-2.522)$ & 0.108 \\
\hline \multirow{3}{*}{ Women } & & 0.014 \\
& HDL $(>40 \mathrm{mg} / \mathrm{dL})$ & $0.453(0.241-0.849)$ & 0.07 \\
& Diabetes duration (years) & $1.066(1.007-1.14)$ & 0.105 \\
& $\mathrm{LDL}(>100 \mathrm{mg} / \mathrm{dL})$ & $1.433(0.89-2.378)$ & 0.040 \\
\hline
\end{tabular}

FBS, fasting blood sugar; HDL, high density lipoprotein; LDL, low density lipoprotein; $\mathrm{HbA}_{1 \mathrm{C}}$, hemoglobin $\mathrm{A}_{1 \mathrm{c}}$; $\mathrm{Cl}$, confidence interval.

${ }^{*} \mathrm{~A}$ forward stepwise procedure was employed, using $\mathrm{HbA}_{1 \mathrm{C}}, \mathrm{HDL}$, LDL, FBS, diabetes duration, TG, cholesterol, systolic blood pressure and diastolic blood pressure (for categorical variables, $\mathrm{HDL}>40 \mathrm{mg} / \mathrm{dL}$, $\mathrm{LDL}>100 \mathrm{mg} / \mathrm{dL}$, triglyceride $>150 \mathrm{mg} / \mathrm{dL}$, cholesterol $>150 \mathrm{mg} / \mathrm{dL}$, systolic blood pressure $>130 \mathrm{mmHg}$, and diastolic blood pressure $>80 \mathrm{mmHg}$ were the reference categories). 
albuminuria. The predictors of albuminuria in men and women (table 3 ) were then studied. Results showed that while diabetes duration, HDL, LDL, and $\mathrm{HbA}_{1 \mathrm{c}}$ influence albuminuria in women, diabetes duration, FBS, and diastolic blood pressure influence albuminuria in men (table 3 ).

\section{Discussion}

The main finding of the present study was the effect of gender on the albuminuria-ischemic heart disease relationship. The odds ratio of having ischemic heart disease according to the presence or absence of albuminuria was highest in men with type 2 diabetes. Furthermore the prevalence of ischemic heart disease was significantly higher in men with albuminuria compared to men without albuminuria. The strength of this study is the large cohort of both the cases and the controls.

Rapid decline in renal function has been repeatedly shown to be more prevalent in men. ${ }^{21-23}$ There are conflicting reports concerning the effect of gender on rate of urinary albumin

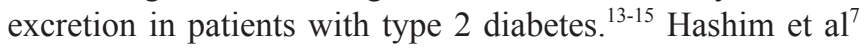
demonstrated that urinary albumin excretion is associated with insulin resistance and cardiovascular risk factors in patients with type 2 diabetes that is more severely pronounced in women. However, some other studies have shown male gender as an independent risk factor for the progression of albuminuria in patients with type 2 diabetes. ${ }^{11,12}$ Villar et al ${ }^{12}$ showed that elderly women have a worse outcome in the progression to end-stage renal disease and death compared to elderly men with type 2 diabetes. Hidden confounders such as lifestyle differences between men and women that have not been included in the studied variables may account for the difference as well. Non-use of angiotensin-converting enzyme inhibitors is an identified risk factor of rapid progression to albuminuria in patients with type 2 diabetes. ${ }^{24}$ Consistently, Larkin et $\mathrm{al}^{25}$ suggested that risk reducing measures, such as taking medications, are underused in women with both type 1 and type 2 diabetes. Cigarette smoking, which is five times more prevalent among Persian men compared to women, ${ }^{26}$ leads to reduced relaxant responses of the cutaneous microcirculation ${ }^{27}$ as well as to blunted basal and stimulated nitric oxide bioactivity. ${ }^{28}$

Consistent with the findings in the present study, De Cosmo et $\mathrm{al}^{29}$ showed that, in patients with type 2 diabetes, increased urinary albumin excretion is associated with cardiovascular risk factors, which is significantly higher in men than in women. In a study on healthy individuals, Verhave et $\mathrm{al}^{30}$ showed that cardiovascular risk factors and urinary albumin excretion rate are significantly correlated only in men. This is the first study demonstrating the effect of gender on the albuminuria-ischemic heart disease relationship in patients with type 2 diabetes. The odds ratio of having albuminuria was significantly higher in men with ischemic heart disease compared to women.

There are a number of theories postulated to explain the prognostic value of albuminuria in the prediction of ischemic heart disease in men with type 2 diabetes. Some believe that this may be due to the deleterious role of androgens in men or the protective role of estrogen in women. Androgens are known to activate the renin-angiotensin system and might cause endothelial cell injury. ${ }^{31}$ Testosterone causes salt and water retention, particularly in elderly men, ${ }^{32,33}$ which may contribute to edema, hypertension, and vascular injury. ${ }^{34}$ Lowered testosterone levels following orchiectomy have been shown to reduce oxidative stress and renal injury after ischemia. ${ }^{35}$ Furthermore, Chandie Shaw et $\mathrm{al}^{36}$ demonstrated that central obesity, which is more frequent in men with metabolic syndrome and type 2 diabetes, is an independent risk factor of albuminuria in healthy individuals. Interestingly, Schneider et $\mathrm{al}^{11}$ demonstrated that nitric oxide availability in the renal circulation is greater in women than in men with type 2 diabetes and is associated with reduced levels of oxidative stress in the renal circulation of women.

The current study showed that while diabetes duration, HDL, LDL, and $\mathrm{HbA}_{1 \mathrm{c}}$ influence albuminuria in women, diabetes duration, FBS, and diastolic blood pressure influence albuminuria in men. Consistent with these findings, some studies have shown that duration of diabetes, poor glycemic control, high serum cholesterol, high triglycerides, low serum HDL, uncontrolled hypertension, and cigarette smoking are important risk factors for the progression to albuminuria. ${ }^{37-43}$ In a previous study, we showed that in type 2 diabetes, men have a higher mean level of urinary albumin excretion rate compared to women. ${ }^{10}$ Observations of that study demonstrated that this difference vanished after adjusting for age and HDL levels. ${ }^{10}$ We believe that HDL plays an important role in the progression to albuminuria in patients with type 2 diabetes. This may also explain the gender differences observed in albuminuria progression. Because men have lower serum HDL levels, they have a higher risk of progression to albuminuria. In the current study, we showed the protective role of serum HDL on albuminuria in women. Future prospective studies on patients with type 2 diabetes may elucidate the role of $\mathrm{HDL}, \mathrm{LDL}, \mathrm{HbA}_{1 \mathrm{c}}$, and diastolic blood pressure on the progression to albuminuria in men and women.

Conversely, we showed lower GFR levels in women compared to men. In a recent study, Afghahi et $\mathrm{al}^{44}$ showed that the majority of patients with type 2 diabetes and renal impairment registered at the Swedish National Diabetes Register were nonalbuminuric. They suggested that the cause-effect relationships observed in cross sectional studies may be confounded by unknown variables. ${ }^{44}$ Donahue et $\mathrm{al}^{45}$ showed that women who progress from normoglycemia to prediabetes have greater endothelial dysfunction, a greater degree of fibrinolysis/thrombosis, and are more hypertensive than men. ${ }^{45}$ It has been shown that women with hypertension have a higher prevalence of other concomitant cardiovascular risk factors. ${ }^{46,47}$ White et al ${ }^{48}$ suggested that the diabetic state is associated with estrogen-stimulated production of superoxide and a reduced level of nitric oxide within the 
vasculature. By controlling for adverse cardiac events, we may have excluded those women who are more genetically susceptible to albuminuria. It seems that urinary albumin excretion rate and the declination in the GFR are not consistent in men and women with type 2 diabetes. Considering the impact of sex steroid hormones, markers of oxidative stress, inflammation, and antioxidants like leptin, C-reactive protein, and HDL, we suggest that diabetes-induced complications may be mediated by different pathways in men and women. This is an interesting topic for future prospective studies.

The limitation of this study is its cross-sectional nature, which precludes the determination of the direction of causality; however, we took advantage of a relatively large sample size and close similarity between groups in most of the confounding variables. Patients in the case and control groups were almost similar regarding the medications they were receiving, although we did not match the cases and controls according to the diabetes, hyperlipidemic, and hypertensive treatment which may have had confounded our findings. In conclusion, we showed the value of albuminuria in the prediction of ischemic heart disease. Moreover, HDL-C, $\mathrm{HbA}_{1 \mathrm{c}}$, and systolic blood pressure influenced the gender-albuminuria relationship in patients with type 2 diabetes. This may add to the understanding of the pathogenesis of diabetes complications in men and women with type 2 diabetes.

\section{References}

1. Deckert T, Feldt-Rasmussen B, Borch-Johnsen K, Jensen T, Kofoed-Enevoldsen A. Albuminuria reflects widespread vascular damage. The Steno hypothesis. Diabetologia 1989;32:219-226.

2. Silva AM, Schaan BD, Signori LU, Plentz RD, Moreno Jr H, Bertoluci MC, Irigoyen MC. Microalbuminuria is associated with impaired arterial and venous endotheliumdependent vasodilation in patients with type 2 diabetes. J Endocrinol Invest 2010;33:696-700.

3. Russo LM, Osicka TM, Bonnet F, Jerums G, Comper WD. Albuminuria in hypertension is linked to altered lysosomal activity and TGF-beta1 expression. Hypertension 2002;39:281-286.

4. Bolajoko EB, Mossanda KS, Adeniyi F, Akinosun O, Fasanmade A, Moropane M. Antioxidant and oxidative stress status in type 2 diabetes and diabetic foot ulcer. S Afr Med J 2008;98:614-617.

5. Ndip A, Rutter MK, Vileikyte L, Vardhan A, Asari A, Jameel M, Tahir HA, Lavery LA, Boulton AJ. Dialysis treatment is an independent risk factor for foot ulceration in patients with diabetes and stage 4 or 5 chronic kidney disease. Diabetes Care 2010;33:1811-1816.

6. Gerstein HC, Mann JF, Yi Q, Zinman B, Dinneen SF, Hoogwerf B, Hallé JP, Young J, Rashkow A, Joyce C, Nawaz S, Yusuf $\mathrm{S}$; HOPE Study Investigators. Albuminuria and risk of cardiovascular events, death, and heart failure in diabetic and nondiabetic individuals. JAMA 2001;286:421-426.

7. Hashim R, Khalil ur R, Ahmed TA, Mushtaq S, Zafar L, Attique M. Microalbumiuria and associated risk factors in type II diabetics. J Coll Physicians Surg Pak 2004;14:84-87.

8. Gu K, Cowie CC, Harris MI. Diabetes and decline in heart disease mortality in US adults. JAMA 1999;281:1291-1297.
9. Donahoe SM, Stewart GC, McCabe CH, Mohanavelu S, Murphy SA, Cannon CP, Antman EM. Diabetes and mortality following acute coronary syndromes. JAMA 2007;298: 765-775.

10. Nakhjavani M, Esteghamati A, Esfahanian F, Aghamohammadzadeh N, Hamidi S, Meysamie A, Abbasi M. Albuminuria and its correlates in an Iranian type 2 diabetic population. Lipids Health Dis 2008;7:28.

11. Schneider MP, Ritt M, Raff U, Ott C, Schmieder RE. Gender is related to alterations of renal endothelial function in type 2 diabetes. Nephrol Dial Transplant 2009;24:3354-3359.

12. Villar E, Chang SH, McDonald SP. Incidences, treatments, outcomes, and sex effect on survival in patients with endstage renal disease by diabetes status in Australia and New Zealand (1991 2005). Diabetes Care 2007;30:3070-3076.

13. Chan NN, Vallance P, Colhoun HM. Endothelium-dependent and -independent vascular dysfunction in type 1 diabetes: role of conventional risk factors, sex, and glycemic control. Arterioscler Thromb Vasc Biol 2003;23:1048-1054.

14. Raile K, Galler A, Hofer S, Herbst A, Dunstheimer D, Busch P, et al. Diabetic nephropathy in 27,805 children, adolescents, and adults with type 1 diabetes: effect of diabetes duration, A1C, hypertension, dyslipidemia, diabetes onset, and sex. Diabetes Care 2007;30:2523-2528.

15. Mackin P, Macleod JM, New JP, Marshall SM. Renal function in long-duration type I diabetes. Diabetes Care 1996;19: 249-251.

16. Brown WV. Microvascular complications of diabetes mellitus: renal protection accompanies cardiovascular protection. Am J Cardiol 2008;102:10L-13L.

17. Kalaitzidis R, Bakris G. Pathogenesis and treatment of microalbuminuria in patients with diabetes: the road ahead. J Clin Hypertens (Greenwich) 2009;11:636-643.

18. Vergouwe Y, Soedamah-Muthu SS, Zgibor J, Chaturvedi N, Forsblom C, Snell-Bergeon JK, Maahs DM, Groop PH, Rewers M, Orchard TJ, Fuller JH, Moons KG. Progression to microalbuminuria in type 1 diabetes: development and validation of a prediction rule. Diabetologia 2010;53: 254-262.

19. Cockcroft DW, Gault MH. Prediction of creatinine clearance from serum creatinine. Nephron 1976;16:31-41.

20. Garrow JS, Webster J. Quetelet's index (W/H2) as a measure of fatness. Int J Obes 1985;9:147-153.

21. Cattran DC, Reich HN, Beanlands HJ, Miller JA, Scholey JW, Troyanov S; Genes, Gender and Glomerulonephritis Group. The impact of sex in primary glomerulonephritis. Nephrol Dial Transplant 2008;23:2247-2253.

22. Neugarten J, Acharya A, Silbiger SR. Effect of gender on the progression of nondiabetic renal disease: a meta-analysis. J Am Soc Nephrol 2000;11:319-329.

23. Remuzzi A, Puntorieri S, Mazzoleni A, Remuzzi G. Sex related differences in glomerular ultrafiltration and proteinuria in Munich-Wistar rats. Kidney Int 1988;34:481-486.

24. Smulders YM, Rakic M, Stehouwer CD, Weijers RN, Slaats $\mathrm{EH}$, Silberbusch J. Determinants of progression of microalbuminuria in patients with NIDDM. A prospective study. Diabetes Care 1997;20:999-1005.

25. Larkin ME, Backlund JY, Cleary P, Bayless M, Schaefer B, Canady J, Nathan DM; Diabetes Control and Complications Trial/Epidemiology of Diabetes Interventions and Complications (DCCT/EDIC) Research Group. Disparity in management of diabetes and coronary heart disease risk factors by sex in DCCT/EDIC. Diabet Med 2010;27: 451-458.

26. Meysamie A, Ghaletaki R, Haghazali M, Asgari F, Rashidi A, Khalilzadeh O, Esteghamati A, Abbasi M. Pattern of tobacco use among the Iranian adult population: results of the national Survey of Risk Factors of Non-Communicable Diseases (SuRFNCD-2007). Tob Control 2010;19:125-128. 
27. Edvinsson ML, Andersson SE, Xu CB, Edvinsson L. Cigarette smoking leads to reduced relaxant responses of the cutaneous microcirculation. Vasc Health Risk Manag 2008;4:699-704.

28. Butler R, Morris AD, Struthers AD. Cigarette smoking in men and vascular responsiveness. Br J Clin Pharmacol 2001;52:145-149.

29. De Cosmo S, Minenna A, Ludovico O, Mastroianno S, Di Giorgio A, Pirro L, Trischitta V. Increased urinary albumin excretion, insulin resistance, and related cardiovascular risk factors in patients with type 2 diabetes: evidence of a sexspecific association. Diabetes Care 2005;28:910-915.

30. Verhave JC, Hillege HL, Burgerhof JG, Navis G, de Zeeuw D, de Jong PE. Cardiovascular risk factors are differently associated with urinary albumin excretion in men and women. J Am Soc Nephrol 2003;14:1330-1335.

31. Ritz E. Cardiovascular risk factors and urinary albumin: vive la petite difference. J Am Soc Nephrol 2003;14:1415-1416.

32. Lundh B, Gardner FH. The effect of testosterone in pharmacological doses on plasma volume and on some serum proteins in patients with sickle cell anemia and in sexually impotent men. Scand J Clin Lab Invest 1971;28: 72-78.

33. Quan A, Chakravarty S, Chen JK, Chen JC, Loleh S, Saini N, Harris RC, Capdevila J, Quigley R. Androgens augment proximal tubule transport. Am J Physiol Renal Physiol 2004;287:F452-459.

34. Caminiti G, Volterrani M, Iellamo F, Marazzi G, Massaro R, Miceli M, Mammi C, Piepoli M, Fini M, Rosano GM. Effect of long-acting testosterone treatment on functional exercise capacity, skeletal muscle performance, insulin resistance, and baroreflex sensitivity in elderly patients with chronic heart failure a double-blind, placebo-controlled, randomized study. J Am Coll Cardiol 2009;54:919-927.

35. Kim J, Kil IS, Seok YM, Yang ES, Kim DK, Lim DG, Park JW, Bonventre JV, Park KM. Orchiectomy attenuates postischemic oxidative stress and ischemia/reperfusion injury in mice. A role for manganese superoxide dismutase. J Biol Chem 2006;281:20349-20356.

36. Chandie Shaw PK, Berger SP, Mallat M, Frolich M, Dekker FW, Rabelink TJ. Central obesity is an independent risk factor for albuminuria in nondiabetic South Asian subjects. Diabetes Care 2007;30:1840-1844.

37. Al-Salman RA, Al-Basri HA, Al-Sayyad AS, Hearnshaw HM. Prevalence and risk factors of albuminuria in Type 2 diabetes in Bahrain. J Endocrinol Invest 2009;32:746-751.

38. Krairittichai U, Potisat S, Jongsareejit A, Sattaputh C. Prevalence and risk factors of diabetic nephropathy among Thai patients with type 2 diabetes mellitus. J Med Assoc Thai 2011;94 Suppl 2:S1-S5.

39. Anan F, Masaki T, Takahashi N, Nakagawa M, Yonemochi H, Eshima N, Saikawa T, Yoshimatsu H. Smoking is associated with urinary albumin excretion: an evaluation of premenopausal patients with type 2 diabetes mellitus. Metabolism 2007;56:179-184.

40. Chuahirun T, Khanna A, Kimball K, Wesson DE. Cigarette smoking and increased urine albumin excretion are interrelated predictors of nephropathy progression in type 2 diabetes. Am J Kidney Dis 2003;41:13-21.

41. Gambaro G, Bax G, Fusaro M, Normanno M, Manani SM, Zanella M, Dangelo A, Fedele D, Favaro S. Cigarette smoking is a risk factor for nephropathy and its progression in type 2 diabetes mellitus. Diabetes Nutr Metab 2001; 14:337-342.

42. Powrie JK, Watts GF, Ingham JN, Taub NA, Talmud PJ, Shaw KM. Role of glycaemic control in development of microalbuminuria in patients with insulin dependent diabetes. BMJ 1994;309:1608-1612.
43. Penno G, Solini A, Bonora E, Fondelli C, Orsi E, Zerbini G, Trevisan R, Vedovato M, Gruden G, Cavalot F, Cignarelli M, Laviola L, Morano S, Nicolucci A, Pugliese G; Renal Insufficiency And Cardiovascular Events (RIACE) Study Group. Clinical significance of nonalbuminuric renal impairment in type 2 diabetes. J Hypertens 2011;29: 1802-1809.

44. Afghahi H, Cederholm J, Eliasson B, Zethelius B, Gudbjornsdottir S, Hadimeri H, Svensson MK. Risk factors for the development of albuminuria and renal impairment in type 2 diabetes--the Swedish National Diabetes Register (NDR). Nephrol Dial Transplant 2011;26:1236-1243.

45. Donahue RP, Rejman K, Rafalson LB, Dmochowski J, Stranges S, Trevisan M. Sex differences in endothelial function markers before conversion to pre-diabetes: does the clock start ticking earlier among women? The Western New York Study. Diabetes Care 2007;30:354-359.

46. Patel PD, Arora RR. Endothelial dysfunction: a potential tool in gender related cardiovascular disease. Ther Adv Cardiovasc Dis 2008;2:89-100.

47. Ong KL, Tso AW, Lam KS, Cheung BM. Gender difference in blood pressure control and cardiovascular risk factors in Americans with diagnosed hypertension. Hypertension 2008;51:1142-1148.

48. White RE, Gerrity R, Barman SA, Han G. Estrogen and oxidative stress: A novel mechanism that may increase the risk for cardiovascular disease in women. Steroids 2010;75:788-793.

\section{Author Affiliations}

Manouchehr Nakhjavani, MD*; Afsaneh Morteza, MD, MPH*,; Yaser Jenab, MD ; Azam Ghaneei, MD*;

Alireza Esteghamati, MD*; Maryam Karimi, $B S^{*}$; Alireza Farokhian, $M D^{\dagger}$

*Endocrinology and Metabolism Research Center (EMRC), Vali-Asr Hospital, Tehran University of Medical Sciences, Tehran, Iran

tDepartment of Cardiology, Imam Hospital Complex, Tehran University of Medical Sciences, Tehran, Iran * Shahid Sadoughi University of Medical Sciences, Yazd, Iran 